\title{
Effects of Serum Calcium Level and Parathyroid Extracts on Phosphate and Calcium Excretion in Hypoparathyroid Patients *
}

\author{
Eugene Eisenberg $\dagger$ \\ (From the Department of Medicine, University of California School of Medicine,
} San Francisco, Calif.)

The known effects of parathyroid hormone on renal excretion of phosphate have tempted some investigators to ascribe a central role to the parathyroid glands in phosphate homeostasis. However, it has been shown that hypoparathyroid patients maintained on vitamin $\mathrm{D}$ are able to increase renal phosphate clearance in a manner similar to normal subjects when their oral phosphate intake is raised (1). The vitamin D used in therapy of this illness is generally believed to be directly responsible for increased renal clearance of phosphate, but such large doses of vitamin D cannot be given without affecting calcium metabolism. The possibility that the serum calcium level could affect phosphate homeostasis was explored by measuring the renal response to raising phosphate intake before and during prolonged calcium infusion in untreated hypoparathyroid patients. The experimental design also afforded an opportunity to measure directly the effect of parathyroid extracts on renal excretion of calcium in man.

\section{Methods}

Six patients with untreated postsurgical hypoparathyroidism and one with untreated idiopathic hypoparathyroidism were studied. Of the six postsurgical patients four had been hypoparathyroid from 1 to 6 years. Two were only 1 week postoperative but have since been shown to have permanent hypoparathyroidism.

The patients received a standard diet containing 1,550

* Submitted for publication September 23, 1964; accepted February 22, 1965.

This work was carried out in the General Clinical Research Center, University of California, grant FR-79 from the Division of Research Facilities and Resources, National Institutes of Health. The studies were partially supported by grants from the Committee on Research, School of Medicine, University of California.

$\dagger$ Address requests for reprints to Dr. Eugene Eisenberg, Department of Medicine, University of California, San Francisco Medical Center, San Francisco, Calif. 94122. $\mathrm{mg}$ of phosphorus throughout the study. Meals were given at 8:00 a.m., 12:00 noon, and 4:30 p.m. No other food was permitted, but tap water was allowed ad libitum. Ambulation and activity were the same each day. Urine was usually collected in two 12-hour periods daily from 8:00 a.m. to 8:00 p.m. and 8:00 p.m. to 8:00 a.m. Blood specimens were taken daily just before breakfast and dinner and, when necessary for monitoring the calcium infusion, before lunch, at bedtime, and during the night. After measurement of phosphate and calcium excretion on this diet the patients received an extra load of phosphate for 1 day. The extra phosphate load given was an additional $1,550 \mathrm{mg}$ of phosphorus in the form of phosphate salts ( $775 \mathrm{mg}$ as sodium basic phosphate and $775 \mathrm{mg}$ as sodium acid phosphate). The salts were given in three doses with meals. Then a 72hour calcium chloride infusion in $0.45 \%$ saline was given. The concentration of calcium chloride was adjusted to achieve and maintain as close to normal blood calcium level as possible. The amount varied from 20 to $75 \mathrm{mEq}$ for a 12-hour period. The volume of infusate was $1 \mathrm{~L}$ every 12 hours. During the third day of calcium infusion an extra load of phosphate was again administered.

In four patients calcium infusion was carried into a fourth day, and hourly urine specimens were obtained. After 3 hours of control collections, parathyroid extract was given and urine collected for four more 1-hour periods. One patient received $200 \mathrm{U}$ of parathyroid extract (PTE) 1 intravenously, another received $400 \mathrm{U}$ of PTE subcutaneously, and two received $300 \mathrm{U}$ of purified parathyroid polypeptide intravenously. ${ }^{2}$ Serum and urine calcium were determined by the method of Loken, Teal, and Eisenberg (2), phosphate by the method of Taussky and Shorr (3), creatinine by the method of Folin and $\mathrm{Wu}$ (4). Sodium and potassium were determined on the Baird flame photometer with an internal lithium standard.

\section{Results}

A representative protocol and data from one patient are shown in Table I and graphic representation of data from another patient in Figure 1.

\footnotetext{
1 Commercial Lilly extract no. 4076-835756.

${ }^{2}$ Kindly supplied by Dr. Claude Arnaud and Dr. H. Rasmussen.
} 
TABLE I

Protocol and data for Patient 357914*

\begin{tabular}{|c|c|c|c|c|c|}
\hline \multirow[b]{2}{*}{ Time } & \multicolumn{2}{|c|}{ Serum } & \multicolumn{3}{|c|}{ Urine } \\
\hline & $\mathrm{Ca}$ & $\mathbf{P}$ & $\mathrm{Ca}$ & $\mathrm{C}_{\mathbf{P}}$ & $\mathrm{C}_{\mathrm{cr}}$ \\
\hline hrs & $m E q / L$ & $\begin{array}{c}m g / 100 \\
m l \\
\text { Before }\end{array}$ & $\begin{array}{l}m E q / h r \\
\text { therapy }\end{array}$ & $m l / \min$ & $m l / \min$ \\
\hline $\mathbf{0}$ & 3.4 & 5.2 & 0.03 & 3.2 & 68 \\
\hline \multicolumn{6}{|c|}{ After extra phosphate intake from 0 to $12 \mathrm{hrs}$} \\
\hline 24 & 3.0 & 5.6 & 0.03 & 3.3 & 77 \\
\hline \multicolumn{6}{|c|}{ After first 24 hrs of iv $\mathrm{CaCl}_{2}$} \\
\hline 48 & 5.6 & 5.6 & 0.82 & 11.8 & 76 \\
\hline \multicolumn{6}{|c|}{ After second 24 hrs of iv $\mathrm{CaCl}_{2}$} \\
\hline 72 & 4.9 & 4.4 & 0.90 & 13.0 & 80 \\
\hline \multicolumn{6}{|c|}{$\begin{array}{c}\text { After third } 24 \text { hours of iv } \mathrm{CaCl}_{2} \text { plus extra phosphate } \\
\text { intake from } 72 \text { to } 84 \text { hrs }\end{array}$} \\
\hline 96 & 5.1 & 4.4 & 1.30 & 26.6 & 92 \\
\hline \multicolumn{6}{|c|}{ Hourly collection from 96 to $103 \mathrm{hrs}$; iv $\mathrm{CaCl}_{2}$ continued } \\
\hline $\begin{array}{r}97 \\
98 \\
99 \\
100\end{array}$ & 4.9 & 4.1 & $\begin{array}{l}1.40 \\
1.40 \\
1.20 \\
1.29\end{array}$ & $\begin{array}{l}22.4 \\
17.6 \\
14.1 \\
14.1\end{array}$ & $\begin{array}{l}96 \\
87 \\
63 \\
64\end{array}$ \\
\hline \multicolumn{6}{|c|}{$99: 30,400 \mathrm{U}$ parathyroid extract subcutaneously } \\
\hline $\begin{array}{l}101 \\
102 \\
103\end{array}$ & $\begin{array}{l}5.3 \\
5.4\end{array}$ & $\begin{array}{l}4.2 \\
4.0\end{array}$ & $\begin{array}{l}1.00 \\
0.59 \\
0.58\end{array}$ & $\begin{array}{l}34.8 \\
36.3 \\
40.5\end{array}$ & $\begin{array}{l}63 \\
73 \\
65\end{array}$ \\
\hline
\end{tabular}

$* \mathrm{C}_{P}=$ phosphate clearance; $\mathrm{C}_{\boldsymbol{C}}=$ creatinine clearance.

A) Effects of calcium infusion (Tables I, II; Figure 1). During the first 8 hours of calcium infusion, the change in serum phosphate was slight, amounting to $+0.6,-0.1,-0.9,+0.4$, and $+0.2 \mathrm{mg}$ per $100 \mathrm{ml}$. With prolonged calcium infusion that maintained the serum calcium at normal levels, the serum phosphate level dropped as the phosphate clearance increased. The serum phosphate fell to normal levels or close to it in all patients. The phosphate clearance rose steadily during the calcium infusion, climbing from the low levels usually associated with untreated hypoparathyroidism to within the normal range in all patients. Urinary calcium excretion rose from low values to rates far in excess of normal, even when serum calcium levels were normal or slightly below normal.

B) Effects of phosphate loading before and during calcium infusion (Table I; Figures 1,2). Oral administration of the extra phosphate load before calcium infusion caused the two acute postoperative cases to develop severe tetany, and this phase of the study was abandoned in them. In the remaining five patients the extra phosphate load caused only slight increase in phosphate clearance. The fasting serum phosphate level taken the next morning was higher (and the serum calcium level fell slightly) in four of the five patients so studied. When an identical phosphate load was given during the third day of calcium infusion, the clearance of phosphate increased markedly. The serum phosphate tended to decrease in spite of additional phosphate load.

C) Effects of parathyroid extract (Tables I, III ; Figure 1). Administration of PTE to two patients and purified parathyroid polypeptide to two patients during maintenance of their serum

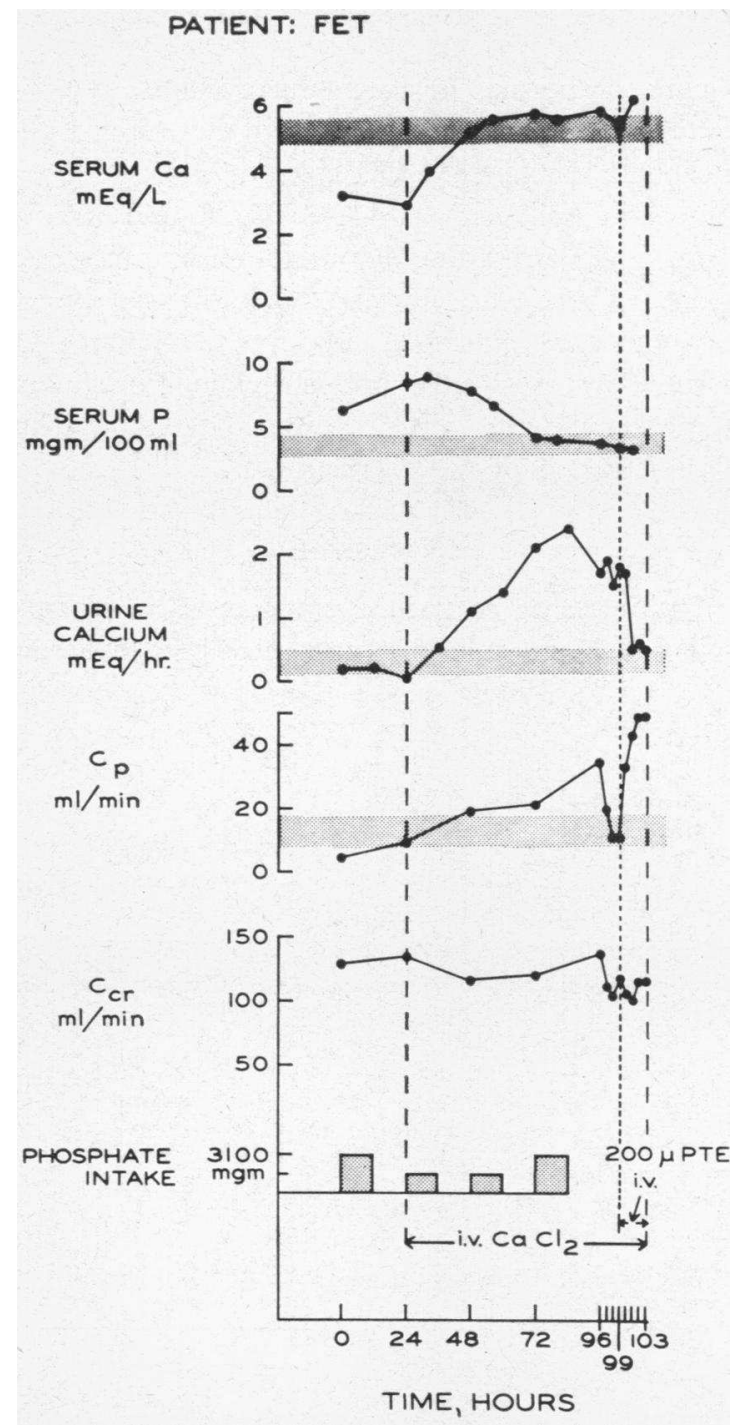

Fig. 1. Graphic Representative of efFects of SERUM CALCIUM LEVEL AND PARATHYROID EXTRACT (PTE) ON Phosphate AND CALCIUM excretion in Patient 308668. The horizontal gray bars represent the mean \pm 2 SD for the normal subjects in this laboratory. 
TABLE II

Effects of calcium infusion on serum phosphate, phosphate clearance, and urinary calcium*

\begin{tabular}{|c|c|c|c|c|c|c|c|c|c|c|}
\hline \multirow[b]{2}{*}{ Patient } & \multicolumn{5}{|c|}{ Before any therapy } & \multicolumn{5}{|c|}{ End of second day of calcium infusion } \\
\hline & $\mathrm{SCa}_{\mathrm{Ca}}$ & SP & $\mathrm{UCa}_{\mathrm{Ca}}$ & $\mathrm{C}_{\mathrm{P}}$ & $\mathrm{C}_{\mathrm{Cr}}$ & $\mathrm{SCa}$ & $\mathrm{SP}$ & $\mathrm{UCa}_{\mathrm{Ca}}$ & $\mathrm{C}_{\mathbf{P}}$ & $\mathrm{C}_{\mathrm{Cr}}$ \\
\hline & $m E q / L$ & $\stackrel{\mathrm{mg} /}{100 \mathrm{ml}}$ & $m E q / h r$ & $m l / m i n$ & $m l / m i n$ & $m E q / L$ & $\stackrel{\mathrm{mg} /}{100 \mathrm{ml}}$ & $m E q / h r$ & $\mathrm{ml} / \mathrm{min}$ & $\operatorname{ml} / \min$ \\
\hline 308668 & 3.20 & 6.3 & 0.20 & 5.2 & 129 & 5.80 & 4.2 & 2.10 & 21.4 & 120 \\
\hline 357914 & 3.40 & 5.2 & 0.03 & 3.2 & 68 & 4.90 & 4.4 & 0.90 & 13.0 & 80 \\
\hline 236911 & 3.00 & 6.1 & 0.05 & 1.8 & 87 & 4.40 & 4.2 & 1.00 & 10.1 & 80 \\
\hline 302542 & 3.80 & 4.2 & 0.07 & 1.5 & 91 & 5.20 & 4.1 & 1.60 & 16.0 & 113 \\
\hline 360799 & 2.55 & 5.9 & 0.08 & 6.2 & 71 & 5.00 & 4.5 & 1.45 & 11.1 & 58 \\
\hline 356654 & 3.30 & 5.6 & 0.20 & 3.0 & 75 & 4.60 & 4.5 & 1.10 & 15.9 & 78 \\
\hline 382432 & 3.80 & 4.3 & 0.03 & 4.2 & 76 & 5.35 & 3.0 & 0.85 & 20.6 & 66 \\
\hline
\end{tabular}

${ }^{*} \mathrm{~S}_{\mathrm{Ca}}=$ serum calcium level; $\mathrm{S}_{\mathrm{P}}=$ serum inorganic phosphate level; $\mathrm{U}_{\mathrm{Ca}}=$ urinary calcium excretion.

calcium at normal levels by intravenous infusion of calcium chloride caused marked elevation of the phosphate clearance. The calcium content of the urine simultaneously fell to $44,31,30$, and $50 \%$ of their values preceding administration of the extracts. There were no significant changes in endogenous creatinine clearance, and sodium and potassium excretion either did not change or tended to increase in the 4 hours immediately following administration of the extracts.

\section{Discussion}

The response of normal subjects to a standard 4-hour calcium tolerance test is a rise in serum
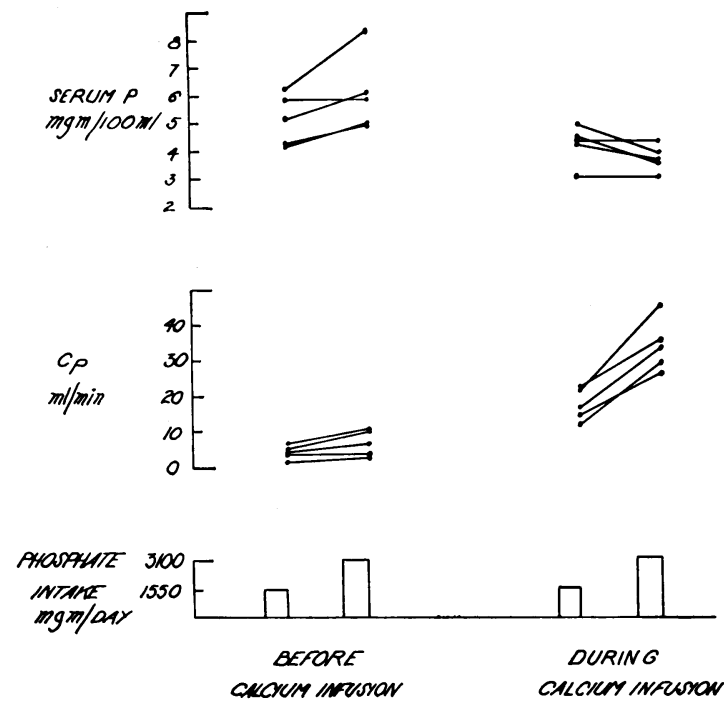

Fig. 2. EFfects of INCREASING Phosphate intake ON SERUM PHOSPHATE LEVEL AND PHOSPHATE CLEARANCE DURING HYPOCALCEMIA (BEFORE CALCIUM INFUSION) AND WITH NORMAL CALCIUM LEVEL (DURING CALCIUM INFUSION). phosphate and a fall in phosphate clearance. In untreated hypoparathyroid patients a rise in both serum phosphate and phosphate clearance is commonly observed (5-8). Lavender and Pullman (9) suggest that the difference in response between normal and hypoparathyroid subjects is accounted for by the level to which the blood calcium is raised. In normal subjects the serum calcium is raised higher, and the deleterious effect of hypercalcemia on glomerular filtration rate would lower phosphate excretion. With the moderate hypercalcemia achieved in the hypoparathyroid subjects the increased serum phosphate would account for the raised phosphate excretion. However, the data above demonstrate that when a normal calcium environment was provided for a longer time, the hypoparathyroid subjects increased phosphate clearance, even though the serum phosphate level fell and creatinine clearance did not significantly change. They also regained the ability to increase phosphate clearance further when phosphate intake was raised. This phosphuresis was accomplished without marked change in

TABLE III

Effect of parathyroid extracts on urinary cation excretion

\begin{tabular}{|c|c|c|c|c|c|c|}
\hline \multirow[b]{2}{*}{ Extract } & \multicolumn{2}{|c|}{ Calcium } & \multicolumn{2}{|c|}{ Sodium } & \multicolumn{2}{|c|}{ Potassium } \\
\hline & C* & $\mathrm{E}^{*}$ & C & $\mathrm{E}$ & $\mathrm{C}$ & $\mathrm{D}$ \\
\hline & \multicolumn{2}{|c|}{$m E q / h r$} & \multicolumn{2}{|c|}{$m E q / h r$} & \multicolumn{2}{|c|}{$m E q / h r$} \\
\hline 200 U PTE iv & 1.70 & $0.53 \dagger$ & 12.8 & $24.1 \dagger$ & 2.8 & $5.9 \dagger$ \\
\hline 400 U PTE subcutaneously & 1.30 & $0.58 \dagger$ & 12.9 & $16.2 \ddagger$ & 6.4 & 6.7 \\
\hline $300 \mathrm{U}$ purified parathyroid & & & & & & \\
\hline hormone (PTH) & 1.00 & $0.31 \dagger$ & 15.8 & 16.0 & 4.4 & $6.6 \ddagger$ \\
\hline $300 \mathrm{U}$ PTH & 1.90 & $0.95 \dagger$ & 6.3 & 6.5 & 3.0 & $5.3 \ddagger$ \\
\hline
\end{tabular}

$* \mathrm{C}=$ mean of three 1 -hour preinjection periods; $\mathrm{E}=$ mean of four 1-hour postinjection periods.

$t \mathrm{p}<0.001$. 
glomerular filtration rate and in spite of the reduced serum phosphate level. Presumably a decrease in tubular resorption of phosphate occurred.

It is clear that changes in phosphate excretion can be induced by dietary means in the absence of both parathyroid function and pharmacologic doses of vitamin $\mathrm{D}$. The mechanism for this homeostatic response is obscure, but it does require a normal or near normal serum calcium level. The ability of vitamin D-treated hypoparathyroid patients to respond to oral phosphate loading would appear to be more directly related to the normal serum calcium level than to the vitamin D. These findings raise the possibility that parathyroid hormone and vitamin $\mathrm{D}$ induce phosphaturia by effects on calcium metabolism or on calcium transport in the renal tubular cells instead of by direct effects on renal tubular excretion of phosphate.

It has been reported that parathyroid hormone increases tubular reabsorption of calcium in the rat (10-12). Widrow and Levinsky (13) showed a similar effect of PTE in the dog but could not reproduce this effect with more purified hormone. There is not uniform agreement on the effect of parathyroid hormone on renal excretion of calcium in man. Gordan, Loken, Blum, and Teal (14) reported a decrease in percentage of tubular reabsorption of calcium in hyperparathyroid patients compared to normal subjects, and Horwith, Rich, Thompson, and Rasmussen (15) reported a slight increase in urinary calcium after administration of partially purified parathyroid hormone. Hiatt and Thompson (16) reported no change in urinary calcium after acute administration of PTE in hypoparathyroid patients even though glomerular filtration rate went up slightly after the extract was given. Kleeman and associates $(17,18)$ reported decreased "calcium clearance" in the presence of normal or increased amounts of parathyroid hormone when contrasted to low or normal amounts, respectively. In the reports by Kleeman and associates the "calcium clearance" was actually the ratio of calcium clearance to inulin clearance, and in many of their studies the serum calcium or glomerular filtration rate was changing rapidly. In those studies where these factors were relatively constant, they assumed that changes in parathyroid function were induced by altering the dietary calcium and phosphate of their subjects.
In the present study four patients whose serum calcium had been held at near steady state by slow intravenous administration of calcium chloride responded to administration of parathyroid extracts with a fall in urinary calcium content without a fall in creatinine clearance and without a fall in sodium excretion. Presumably, a rise in tubular reabsorption of calcium occurred. Evidence corroborating such an effect of parathyroid hormone on renal tubular resorption of calcium is provided by the uniform finding of hypercalciuria in all patients during calcium infusion, even though the serum calcium never quite reached normal level. In these patients the hypercalciuria could not be due to the gluconate ion $(19,20)$ or to excessive vitamin $\mathrm{D}(21)$. This observation supports the suggestion of Bernstein, Kleeman, and Maxwell (18) that the hypercalciuria seen in hypoparathyroid patients treated with vitamin $D(21)$ is not due to a direct effect of vitamin $\mathrm{D}$ on tubular reabsorption of calcium but to elevation of the serum calcium towards normal in the absence of the parathyroid gland.

\section{Summary}

Seven patients with untreated hypoparathyroidism were given prolonged calcium infusion. Calcium infusion alone over a period of 48 hours raised the phosphate clearance to normal and lowered the serum phosphate. Before calcium infusion, an oral phosphate load raised phosphate clearance only slightly. When an oral phosphate load was given during calcium infusion, the kidneys were able to excrete it in normal fashion. A mechanism for phosphate homeostasis that does not include the parathyroid glands exists. Since phosphaturia can be induced by maintenance of a normal serum calcium alone, the phosphaturic action of parathyroid hormone and vitamin $\mathrm{D}$ may be due to more basic action on calcium transport. Administration of parathyroid extracts to four patients while the calcium was maintained at a normal level by calcium infusion caused the urinary calcium to decrease significantly.

\section{Acknowledgment}

Assistance for the chemical determinations was provided by Miss Patricia Wright. 


\section{References}

1. Halden, A., E. Eisenberg, and S. Gordan. Parathyroid hormone and phosphate homeostasis in man. Acta endocr. (Kbh.) 1964, 46, 285.

2. Loken, H., J. S. Teal, and E. Eisenberg. Flame spectrophotometry of calcium with reversed oxyacetylene flame. Application to serum and urine. Analyt. Chem. 1963, 35, 875.

3. Taussky, H. H., and E. Shorr. A microcolorimetric method for the determination of inorganic phosphorus. J. biol. Chem. 1953, 202, 675.

4. Folin, O., and $\mathrm{H}$. Wu. A system of blood analysis. J. biol. Chem. 1919, 38, 81.

5. Howard, J. E., T. R. Hopkins, and T. B. Connor. On certain physiologic responses to intravenous injections of calcium salts into normal, hyperparathyroid and hypoparathyroid persons. J. clin. Endocr. 1953, 13, 1.

6. Goldman, R., and S. H. Bassett. Effect of intravenous calcium gluconate upon the excretion of calcium and phosphorus in patients with idiopathic hypoparathyroidism. J. clin. Endocr. 1954, 14, 278.

7. Kyle, L. H., M. Schaaf, and L. A. Erdman. The metabolic effects of intravenous administration of calcium. J. Lab. clin. Med. 1954, 43, 123.

8. Hiatt, H. H., and D. D. Thompson. Some effects of intravenously administered calcium on inorganic phosphate metabolism. J. clin. Invest. 1957, 36, 573.

9. Lavender, A. R., and T. N. Pullman. Changes in inorganic phosphate excretion induced by renal arterial infusion of calcium. Amer. J. Physiol. 1963, 205, 1025.

10. Talmage, R. V., and F. W. Kraintz. Progressive changes in renal phosphate and calcium excretion in rats following parathyroidectomy or parathyroid administration. Proc. Soc. exp. Biol. (N. Y.) 1954, 87, 263.

11. Talmage, R. V., F. W. Kraintz, and G. D. Buchanan. Effect of parathyroid extract and phosphate salts on renal calcium and phosphate excretion after parathyroidectomy. Proc. Soc. exp. Biol. (N. Y.) $1955,88,600$.
12. MacIntyre, I., S. Boss, and V. A. Troughton. Parathyroid hormone and magnesium homeostasis. Nature (Lond.) 1963, 198, 1058.

13. Widrow, S. H., and N. G. Levinsky. The effect of parathyroid extract on renal tubular calcium reabsorption in the dog. J. clin. Invest. 1962, 41, 2151.

14. Gordan, G. S., H. F. Loken, A. Blum, and J. S. Teal. Renal handling of calcium in parathyroid disorders. Metabolism 1962, 11, 94.

15. Horwith, M., C. Rich, D. D. Thompson, and H. Rasmussen. Renal effects of purified bovine parathyroid extract in The Parathyroids, R. O. Greep, and R. V. Talmage, Eds. Springfield, Ill., Charles C Thomas, 1961, pp. 415-421.

16. Hiatt, H. H., and D. D. Thompson. The effects of parathyroid extract on renal function in man. J. clin. Invest. 1957, 36, 557.

17. Kleeman, C. R., D. Bernstein, R. Rockney, J. Dowling, and M. H. Maxwell. Studies on the renal clearance of diffusible calcium and the role of the parathyroid glands in its regulation. Yale J. Biol. Med. 1961, 34, 1.

18. Bernstein, D., C. R. Kleeman, and M. H. Maxwell. The effect of calcium infusions, parathyroid hormone, and vitamin $\mathrm{D}$ on renal clearance of calcium. Proc. Soc. exp. Biol. (N. Y.) 1963, 112, 353.

19. Howard, P. J., W. S. Wilde, and R. L. Malvin. Localization of renal calcium transport; effect of calcium loads and of gluconate anion on water, sodium and potassium. Amer. J. Physiol. 1959, 197, 337.

20. Bernstein, D., C. R. Kleeman, R. E. Cutler, J. T. Dowling, and M. H. Maxwell. Comparison of renal clearance of calcium during infusions of calcium chloride and calcium gluconate. Proc. Soc. exp. Biol. (N. Y.) 1962, 110, 671.

21. Litvak, J., M. P. Moldawer, A. P. Forbes, and P. H. Henneman. Hypocalcemic hypercalciuria during vitamin $\mathrm{D}$ and dihydrotachysterol therapy of hypoparathyroidism. J. clin. Endocr. 1958, 18, 246. 